\title{
Marked and Isolated Hyperprolactinemia Revealing Autoimmune Thyroiditis
}

\author{
Salem Bouomrani ${ }^{1,2, *}$, Wided Letaief ${ }^{2,3}$ \\ ${ }^{1}$ Department of Internal medicine. Military Hospital of Gabes, Gabes, Tunisia \\ ${ }^{2}$ Sfax Faculty of Medicine. University of Sfax, Sfax, Tunisia \\ ${ }^{3}$ Department of Obstetrics and Gynecology, Regional Hospital of Gabes, Mtorrech, Tunisia
}

*Corresponding Author: Salem Bouomrani, Department of Internal medicine. Military Hospital of Gabes, Gabes, TunisiaSfax Faculty of Medicine, University of Sfax, Sfax, Tunisia, Email: salembouomrani@yahoo.fr

\begin{abstract}
Hyperprolactinema due to primary hypothyroidism is common and variously estimated by series: 0 to $57 \%$. It is usually mild or moderate and is explicated by the stimulatory effect of thyrotropin-releasinghormone on the lactotroph cells of the pituitary.

Observations of primary hypothyroidism with secondary marked hyperprolactinemia are exceptional. They pose a real diagnostic challenge for health professionals and sometimes cause diagnostic and therapeutic errors. We report the original observation of a marked and isolated hyperprolactinemia as the first manifestation revealing autoimmune thyroiditis (Hashimoto's thyroiditis) in 32-year-old Tunisian woman with no pathological medical history. Better knowledge of this association by health professionals helps to avoid treatment errors, and sometimes even unnecessary surgery.
\end{abstract}

Keywords: Hyperprolactinema, primary hypothyroidism, autoimmune thyroiditis, Hashimoto's thyroiditis, galactorrhea.

\section{INTRODUCTION}

Hyperprolactinema due to primary hypothyroidism is common [1,2], but is usually mild or moderate [1]. It is explicated by the stimulatory effect of thyrotrophic-releasinghormone (TRH) on the lactotroph cells of the pituitary $[1,2]$. This hormone (TRH) is overproduced in primary hypothyroidism because of the loss of thyroxin feedback inhibition, causing secondary pituitary hyperplasia/enlargement [1].

The prevalence of hyperprolactinemia associated with primary hypothyroidism is variously estimated by the series; it goes from 0 to $57 \%$ [3]. Observations of primary hypothyroidism with marked hyperprolactinemia are exceptional $[1,2$,$] . They$ pose a real diagnostic challenge for health professionals and sometimes cause diagnostic and therapeutic errors that can last for decades $[1,4]$.

We report the original observation of a marked and isolated hyperprolactinemia which was the first manifestation revealing an autoimmune thyroiditis.

\section{CASE Report}

A 32-year-old Tunisian woman with no pathological medical history was explored by her family doctor for persistent galactorrhea for 9 months. The somatic examination was without significant abnormalities, in particular the ophthalmological and neurological examination. Prolactin was increased to $146.18 \mathrm{ng} / \mathrm{ml}$ (normal between 1.3 and $25 \mathrm{ng} / \mathrm{ml}$ ). The patient was put on Cabergoline $(0.5 \mathrm{mg} /$ week $)$ without pituitary exploration. No improvement was noted.

She consulted our department a month later for asthenia with weight gain and persistence of galactorrhea.

Physical examination noted marked psychomotor slowing, dry skin, loss of eyebrow tails, hoarse voice, and macroglossia.

The biological assessment objectified a deep primary hypothyroidism with Thyroidstimulating hormone $(\mathrm{TSH})>60 \mu \mathrm{UI} / \mathrm{ml}$ and 
free thyroxine at $1.55 \mathrm{pmol} / \mathrm{l}$. The anti-thyroid antibodies were positive: anti-thyroglobulin at $83.4 \mathrm{IU} / \mathrm{ml}$ and anti-thyroperoxidase at 137.3 $\mathrm{IU} / \mathrm{ml}$. The thyroid ultrasound showed a moderately enlarged thyroid with a heterogeneous appearance suggestive of chronic thyroiditis.

The other basic laboratory tests were within normal limits: leukocytes, platelets, hemoglobin, blood sugar, calcemia, ionogram, transaminases, uric acid, creatinine, muscle enzymes, lipid parameters, and electrophoresis of serum proteins.

The hormonal assays objectified hyperprolactinemia at $88 \mathrm{ng} / \mathrm{ml}$, without other abnormalities (normal follicle stimulating hormone, luteinizing hormone, and growth hormone). Pituitary magnetic resonance imaging did not show adenoma or hyperplasia.

The diagnosis of chronic autoimmune thyroiditis (Hashimoto's thyroiditis) complicated by secondary hyperprolactinemia was therefore retained. The patient was treated with levothyroxine in progressive doses up to 200 $\mu \mathrm{g} / \mathrm{d}$ allowing normalization of TSH. The outcome of hyperprolactinemia was also favorable with disappearance of galactorrhea and normalization of the prolactin level after two months of treatment with levothyroxine (prolactin at $18.18 \mathrm{ng} / \mathrm{ml}$ ).

\section{DISCUSSION}

The association between hyperprolactinemia and primary hypothyroidism is far from uncommon $[1,2]$. This association was noted with both overt [5] and subclinical hypothyroidism [2-6]. It remains significant even after excluding other possible causes of prolactin increase. Indeed, in the Hekimsoy $\mathrm{Z}$ et al series, and even after exclusion of patients with medical reasons for having elevated prolactin levels, lactating, and pregnant women, the prevalence of hyperprolactinemia in patients with newly diagnosed hypothyroidism was $36 \%$ in overt forms and $22 \%$ in subclinical forms [5]. Similarly, a positive correlation was found between prolactinemia and TSH levels in all studies whatever the clinical presentation of hypothyroidism: overt or subclinical [3, 5, and 6].

Conversely, autoimmune hypothyroidism appears to be significantly more common in women followed for prolactinoma: 29.9\% versus $10.4 \%$ in age-matched healthy women $(p=0.0002)$ [7]. These results suggest a potential immunomodulatory action of prolactin.
This effect was proven in experimental in vitro studies [7].

Hyperprolactinemia and its clinical consequences (menorrhagia, galactorrhea, and secondary amenorrhea) may be the first signs of hypothyroidism [4, 8, and 9]. A misunderstanding of this association can lead to errors with significant diagnostic delay (13 years in the observation of Chan AW et al) [8], as well as to inappropriate therapeutic conduct: medical treatment by dopaminergic agonists, or even unjustified pituitary surgery $[8,9]$.

Hyperprolactinemia secondary to primary hypothyroidism is generally mild and the resulting pituitary hyperplasia is also usually minimal. In rare cases, this hyperprolactinemia can be very marked $[1,2]$ and cause significant pituitary enlargement making the diagnosis more difficult. Real cases of "pseudoprolactinoma" simulating a true sellar mass have been reported [1].

This hyperprolactinemia associated with primary hypothyroidism is always of good prognosis, and the evolution under thyroxin treatment is towards the normalization of prolactin and the disappearance of pituitary hyperplasia $[3,5,8]$.

\section{CONCLuSiON}

Thus screening for thyroid function (thyroid hormones and anti-thyroid autoantibodies) is justified for any hyperprolactinemia, even in the absence of any signs of hypothyroidism, before considering a specific medical or surgical management for this condition.

Better knowledge of this association by health professionals helps to avoid treatment errors, and sometimes even unnecessary surgery.

\section{REFERENCES}

[1] Ansari MS, Almalki MH. Primary Hypothyroidism with Markedly High Prolactin. Front Endocrinol (Lausanne). 2016; 7:35.

[2] Olive KE, Hennessey JV. Marked hyperprolactinemia in subclinical hypothyroidism. Arch Intern Med. 1988; 148 (10):2278-9.

[3] Sharma LK, Sharma N, Gadpayle AK, Dutta D. Prevalence and predictors of hyperprolactinemia in subclinical hypothyroidism. Eur $\mathbf{J}$ Intern Med. 2016; 35:106-110.

[4] Aziz K, Shahbaz A, Umair M, Sharifzadeh M, Sachmechi I. Hyperprolactinemia with Galactorrhea Due to Subclinical Hypothyroidism: 
The importance of Chakras and Energy Imbalances Correction in the Prevention and Treatment of Gestational Diabetes

A Case Report and Review of Literature. Cureus. 2018; 10(5):e2723.

[5] Hekimsoy Z, Kafesçiler S, Guçlu F, Ozmen B. The prevalence of hyperprolactinaemia in overt and subclinical hypothyroidism. Endocr $\mathrm{J}$. 2010; 57(12):1011-5.

[6] Sirohi T, Singh H. Estimation of serum prolactin levels and determination of prevalence of hyperprolactinemia in newly diagnosed cases of subclinical hypothyroidism. J Family Med Prim Care. 2018; 7(6):12791282.

[7] Elenkova A, Atanasova I, Kirilov G, Natchev $\mathrm{E}$, Ivanova $\mathrm{R}$, Kovatcheva $\mathrm{R}$, et al. Autoimmune hypothyroidism is three times more frequent in female prolactinoma patients compared to healthy women: data from a crosssectional case-control study. Endocrine. 2017; 57(3):486-493.

[8] Chan AW, MacFarlane IA, Foy PM, Miles JB. Pituitary enlargement and hyperprolactinaemia due to primary hypothyroidism: errors and delays in diagnosis. Br J Neurosurg. 1990; 4(2):107-12.

[9] Rajput R, Sehgal A, Gahlan D. Reversible thyrotroph hyperplasia with hyperprolactinemia: A rare presenting manifestation of primary hypothyroidism. Indian J Endocrinol Metab. 2012; 16(6):1037-9.

Citation: Salem Bouomrani, Wided Letaief, Marked and Isolated Hyperprolactinemia Revealing Autoimmune Thyroiditis. ARC Journal of Diabetes and Endocrinology. 2019; 5(2):21-23. doi:dx.doi.org/10.20431/2455-5983. 0502004.

Copyright: (C) 2019 Authors. This is an open-access article distributed under the terms of the Creative Commons Attribution License, which permits unrestricted use, distribution, and reproduction in any medium, provided the original author and source are credited. 